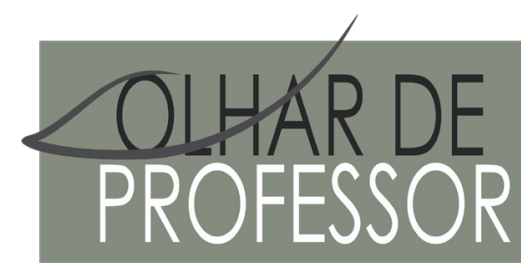

DOI: 10.5212/OLHARPROFR.v23.2020.15840.209209228098.0717

\title{
ANÁLISES DE PESQUISAS SOBRE A EDUCAÇ̃̃O ESPECIAL INCLUSIVA: A IINJDIFERENCIAÇ̃̃O E O PRECONCEITO
}

\author{
RESEARCHES ANALYSIS ON SPECIAL AND INCLUSIVE EDUCATION: THE [INJDIFFERENTIATION \\ AND THE PREJUDICE \\ ANÁLISIS DE LAS INVESTIGACIONES SOBRE LA EDUCACIÓN ESPECIAL INCLUSIVA: LA [EN] \\ DIFERENCIACIÓN Y EL PREJUICIO
}

\section{MARA SALGADO* DIVINO JOSÉ DA SILVA*}

\begin{abstract}
Resumo: $\mathrm{O}$ artigo apresenta as análises das publicações que relatam investigações empíricas de três grupos brasileiros que são referências para a Educação Especial Inclusiva: o Laboratório de estudos sobre o Preconceito, o Observatório Nacional de Educação Especial e o Laboratório de Estudos e Pesquisas em Ensino e Diferença. O percurso teórico-metodológico contou com a pesquisa documental bibliográfica para a seleção dos artigos e as análises apoiam-se na Teoria Crítica da Sociedade e em autores do marco temático da Educação Especial Inclusiva. Os resultados indicam duas categorias indissociáveis: a primeira diz respeito ao preconceito que atravessa as relações entre as crianças, mas também entre os professores e os alunos; a segunda refere-se à sensação de insegurança e despreparo dos professores para formularem atividades especiais e promoverem a inclusão dos alunos com necessidades especiais.
\end{abstract}

Palavras-chave: Educação especial inclusiva. Preconceito. Teoria crítica da sociedade.

\begin{abstract}
The article presents the analyzes of publications that report empirical researches of three Brazilian groups that are references for Special and Inclusive Education: the Laboratório de estudos sobre o Preconceito, the Observatório Nacional de Educação Especial and the Laboratório de Estudos e Pesquisas em Ensino e Diferença. The theoretical-methodological course included bibliographical documentary research for the selection of articles and the analyzes are based on the Critical Theory of Society and on authors from the thematic content of Special and Inclusive Education. The results indicate two inseparable categories: the first concerns the prejudice that runs through the relationships between children, but also between teachers and students; the second refers to the feeling of insecurity and unpreparedness of teachers to formulate special activities and promote the inclusion of students with special needs.
\end{abstract}

Keywords: Special and inclusive education. Prejudice. Critical theory of society.

Resumen: El artículo presenta los análisis de publicaciones que informan investigaciones empíricas de tres grupos brasileños que son referencias para la Educación Especial en la perspectiva de la Inclusión: el Laboratório de estudos sobre o Preconceito, el Observatório Nacional de Educação Especial y el Laboratório de Estudos e

\footnotetext{
* Doutora em Educação. Pós-doutoranda (PNPD/CAPES) no Programa de Pós-graduação em Educação da Universidade Estadual Paulista “Júlio de Mesquita Filho” - UNESP/FCT/Presidente Prudente/SP e Professora de Psicologia da Educação. Universidade do Estado de Minas Gerais - UEMG/Divinópolis. marasalgado.ms@gmail.com.

${ }^{* *}$ Doutor em Educação. Professor de Filosofia da Educação do Departamento de Educação e Programa de Pós-Graduação em Educação da FCT/UNESP/Presidente Prudente, SP. divino.silva@unesp.br.
} 
Pesquisas em Ensino e Diferença. El camino teórico-metodológico incluyó investigación documental bibliográfica para la selección de artículos y los análisis se basan en la Teoría Crítica de la Sociedad y en autores del marco temático de la Educación Especial Inclusiva. Los resultados indican dos categorías inseparables; la primera se refiere al prejuicio que atraviesa las relaciones entre los niños, pero también entre los profesores y los alumnos; la segunda se refiere a la sensación de inseguridad y despreparación de los profesores para formular actividades especiales y promover la inclusión de los alumnos con necesidades especiales.

Palabras-clave: Eeducación especial inclusiva. Prejuicios. Teoría crítica de la sociedad.

\section{NOTAS INICIAIS}

Este artigo ${ }^{1}$ apresenta resultados da pesquisa ${ }^{2}$ cujo objetivo foi analisar publicações resultantes de investigações empíricas sobre a Educação Especial Inclusiva de três grupos científicos brasileiros que são referências para o tema: o Laboratório de estudos sobre o Preconceito (LaEP/USP), o Observatório Nacional de Educação Especial (ONEESP/UFSCAR) e o Laboratório de Estudos e Pesquisas em Ensino e Diferença (LEPED/UNICAMP). O texto estrutura-se em dois momentos. O primeiro contextualiza a Educação Especial Inclusiva vigente no Brasil e suas implicações quanto ao enfrentamento do preconceito, a partir do marco temático da Educação Especial Inclusiva e de autores fundamentados na Teoria Crítica da Sociedade. O segundo traz as análises dos artigos publicados pelos laboratórios mencionados, com foco nas manifestações explícitas e implícitas do preconceito no contexto em tela.

A hipótese inicial da pesquisa era de que seria possível identificar nos artigos a serem analisados aspectos dos processos de aprendizagem e interação social concernentes às faculdades do pensamento que atuam mais fortemente na infância, a saber, as faculdades da mimese, da imaginação e da memória. Com base em estudos que abordam a temática da Educação Especial (AGUIAR, 2003, ANHÃO; PFEIFER; SANTOS, 2010, QUEIROZ; ENUMO; PRIMI, 2013), atividades e comportamentos que podem ser relacionadas às faculdades mencionadas, como, por exemplo, as que envolvem imitação, jogo, dança, atividades lúdicas e de comunicação, compõem o cenário da educação na infância e podem contribuir com a aprendizagem e a interação social de crianças consideradas com necessidades educativas especiais atendidas em escolas regulares, indicando, assim, um possível caminho para propostas pedagógicas inclusivas. Indagou-se, então, se tais aspectos estavam presentes em atividades e práticas pedagógicas contempladas nas pesquisas empíricas dos laboratórios estudados, de modo a contribuir para a superação do preconceito que permeia o contexto da Educação Especial na perspectiva da inclusão.

A fim de verificar essa hipótese, foi fundamental recuperar algumas discussões teóricas. Nos escritos sobre a infância de autores como Theodor W. Adorno e de Walter Benjamin, é possível encontrar uma constelação de elementos que povoam o campo transitório da experiência infantil e resguardam as contradições constituintes da racionalidade esclarecida suscitadas ora para justificar a realidade, ora para resistir a ela. Os jogos, as brincadeiras, a imitação e representação, a imaginação, a memória, a narração, a linguagem, a repetição, a coleção, os sentidos corporais são elementos que mobilizam as faculdades da mimese, da imaginação e da memória ${ }^{3}$. Todos esses elementos aparecem nas obras dos autores da Teoria Crítica da Sociedade como representantes de uma dinâmica racional específica, reveladora de uma forma intelectual-sensível de se relacionar com o próprio corpo, com o outro e com o mundo, operando numa outra face da razão, mais mimética, imaginativa e rememoradora de desejos infantis proscritos no processo civilizatório. A não obstrução de tais faculdades, em especial na infância, pode facilitar caminhos

\footnotetext{
${ }^{1}$ Uma versão preliminar deste texto, intitulada "Diferença e Preconceito na Educação Especial Inclusiva na infância: O que as pesquisas apontam?”, foi apresentada e publicada nos anais do VIII Simpósio Internacional em Educação e Filosofia - Entre o governo das diferenças e os corpos ingovernáveis: potência da vida na Educação, realizado em agosto de 2019 na UNESP/Marília.

${ }^{2}$ Pesquisa desenvolvida no Estágio de Pós-Doutorado com financiamento da CAPES/PNPD na UNESP/ FCT/Presidente Prudente, no Programa de Pós-Graduação em Educação, linha de pesquisa Desenvolvimento humano, diferença e valores, sob a supervisão do coautor deste artigo, professor Dr. Divino José da Silva.

${ }^{3}$ Um estudo mais detalhado das operações das faculdades da mimese, imaginação e memória, fundamentado na perspectiva da Teoria Crítica da Sociedade, pode ser encontrado em Salgado (2017).
} 
para a identificação com o outro, estabelecendo bases não agressivas para a afetividade e, nisso, para o abrigo da diferença e suas fragilidades nas relações humanas (SALGADO, 2017).

Nesse sentido, a infância, como uma outra forma de operar da razão, manifesta as tensões de inclusão e exclusão que se atualizam na história humana e oferece uma via importante para a conhecida crítica empreendida pelos autores frankfurtianos à rigidez do pensamento e à frieza, instauradas dialeticamente com o progresso da razão esclarecida e das quais decorrem a indiferenciação e o preconceito (ADORNO; HORKHEIMER, 1985).

\section{EDUCAÇÃO ESPECIAL INCLUSIVA: MARCAS DA EDUCAÇ̃̃O PARA A CINJDIFERENÇA}

As políticas de Educação Especial na perspectiva da Inclusão representam um movimento teórico, metodológico e cultural que busca responder às reivindicações por direitos humanos de condições igualitárias para todos os indivíduos. Tais reivindicações foram apresentadas, em especial, no Ocidente, a partir de 1948, impulsionadas pelo devastador panorama pós Segunda Guerra Mundial, em que as consequências da naturalização do preconceito e da exclusão tornaram-se desnudas (COMFOR, 2015).

Os documentos legais produzidos na política educacional de cada país compõem um debate em curso mundialmente, em prol da diminuição da exclusão de grupos historicamente isolados e discriminados por suas condições de fragilidade frente às exigências de produtividade social. Nesse sentido, cada marco legal dos programas políticos educacionais com a finalidade de superar a dicotomia entre educação regular e especial avança na compreensão acerca das necessidades educativas especiais e das inter-relações sociais, considerando os aspectos materiais, conceituais, terminológicos, metodológicos e linguísticos constituintes do paradigma proveniente da interação entre especialistas, políticos, intelectuais e movimentos sociais (BRASIL, 2007).

No Brasil, a partir de 2003, quando o Ministério da Educação cria o Programa Educação Inclusiva: direito à diversidade (BRASIL, 2008), as políticas que norteiam o estabelecimento da educação especial adotam a perspectiva da inclusão, ampliando a atenção aos grupos de atendimento a fim de incluir a todos, sem exceção, no sistema regular de ensino. Deste modo, o sistema passa a se adaptar ao aluno, e não o contrário, conforme a perspectiva da integração que antecedeu a orientação inclusiva no Brasil e atualmente é utilizada como parâmetro em outros países. Na perspectiva da inclusão, o programa político educacional passa a considerar não só os alunos com deficiências físicas ou intelectuais, mas também a classe econômica e social, o gênero, a etnia, a raça, bem como as estratégias para o atendimento de forma igualitária oferecidas na educação em todas as fases do ensino (AMIRALIAN, 2005).

Vale ressaltar que as políticas da Educação Especial Inclusiva não se restringem às normas estruturantes da organização do sistema de ensino, mas abrangem um conjunto de valores, ideias, conhecimentos científicos e saberes culturais que fundamentam as mudanças em determinada realidade histórica. Por isso, é exigida a reflexão acerca de tais políticas e da práxis educacional que delas decorre, sem, contudo, desconsiderar os estereótipos e preconceitos que atravessam a dinâmica estabelecida entre os agentes educacionais nos processos de mediação social (COMFOR, 2015).

A questão de um projeto político de educação especial e inclusiva não estava colocada no tempo de Theodor W. Adorno, representante da Teoria Crítica da Sociedade. Contudo, ao reivindicar uma educação para a emancipação, Adorno (1995) afirmava que o único princípio educacional capaz de evitar a repetição do preconceito, da frieza, da violência que excluem a diferença humana, levados às últimas consequências em Auschwitz, é o da autonomia. Trata-se da capacidade do pensamento em reconhecer suas cicatrizes e superar o medo que fundamenta os estereótipos fixados na cultura e, por esse caminho, de refletir sobre as condições de repressão e coerção estabelecidas socialmente que obstam as possibilidades de realização do indivíduo, de sua diferenciação.

Com base em tal entendimento, é indispensável concentrar esforços para trazer à consciência os motivos que permitiram Auschwitz. No âmbito da educação, não parece haver outro caminho senão o de uma formação voltada para as possibilidades de autodeterminação de seus indivíduos e contrárias ao preconceito e à frieza estabelecidos socialmente. Um princípio educacional que, desde Kant, vem sendo 
reivindicado como um esclarecimento emancipador, e cuja origem, conforme identificada pelos autores da Teoria Crítica da Sociedade, reside na autorreflexão crítica acerca da racionalidade - racionalidade essa que possibilitou a permanência da barbárie anacronicamente na organização social. Dessa forma, a meta para esse princípio educacional deve ser orientada pela busca da desbarbarização dos indivíduos, ou seja: possibilitar condições objetivas para que esses elaborem o medo recalcado da própria fragilidade e seu consequente estado de agressividade primitiva que ameaça a civilização com a fúria de indivíduos dispostos a golpear uns aos outros (ADORNO, 1995).

A fúria empreendida pelo fascismo na Alemanha de Hitler contra todo o tipo de fragilidade-identificada nos judeus, ciganos, negros, homossexuais, deficientes físicos e intelectuais e comunistas, ou seja, os tipos sociais que de alguma forma poderiam ser estigmatizados como "desviantes" da norma orientadora prevalecente na sociedade da produtividade capitalista, tanto pela via econômica como moral - não só ainda está presente na atualidade como vem perdendo o constrangimento de persistir, conforme dá exemplo o momento truculento atual da política brasileira e mundial. Desse modo, a realidade existente não superou a indicação de Adorno (1995) de que, para evitar um estado que culmine na segregação para o extermínio, é necessário investir esforços educacionais logo na primeira infância, com vistas às brechas para a resistência ao domínio da razão instrumentalizada na formação humana que, ao longo da escolarização, enfraquece a sensibilidade para lidar com a diferença e a fragilidade nas relações humanas (ADORNO; HORKHEIMER, 1985).

O princípio central que ampara as políticas educacionais em Educação Especial na perspectiva da Inclusão é o de oferecer e garantir as condições adequadas ao acesso, à permanência e à qualidade para todos os alunos, com e sem deficiências, de modo a possibilitar o melhor desenvolvimento das potencialidades de aprendizagem e de interação social de cada aluno de acordo com suas necessidades especiais específicas. Trata-se de um investimento para atender os direitos fundamentais de todos, contribuindo com uma educação capaz de criar e desenvolver condições para a desmistificação da homogeneidade social (MONTOAN, 2013). Caso os agentes educacionais não se contentem com a indispensável prescrição no âmbito legal, tal caminho pode reivindicar meios para a diminuição da formação do preconceito e dos estigmas que incidem sobre os sujeitos a partir dos estereótipos fixados socialmente e reproduzidos nas instituições de mediação social, em especial, na família, na escola e na mídia.

Segundo Amiralian (2005), os estigmas e estereótipos manifestam a fragilidade do humano e, historicamente, constituíram a cultura da vergonha e da culpa nas relações sociais. Na perspectiva da educação inclusiva defendida pela autora, a escola, como instituição de mediação social que recebe os indivíduos desde o início de sua formação, resguarda a possibilidade de refletir acerca das mudanças de atitudes para com a diferença e, assim, acolher “o estranho" que a organização social tratou historicamente de negar, adaptar e excluir. Nesse movimento, a cultura da vergonha e da culpa abriria brechas para um princípio de envolvimento afetivo e de preocupação com o bem-estar do outro, diminuindo a rigidez das bases racionais que formam o preconceito e dificultam o estabelecimento da amizade.

De acordo com Crochík (1996), o preconceito manifesta-se em comportamentos de exclusão, insultos, perseguição e humilhação de uns com os outros. Desse modo, ele é definitivo em impedir que o cuidado e o compartilhamento da diferença e fragilidade se estabeleçam entre as pessoas. Quem recebe o preconceito é atingido na alma, no mais íntimo de sua psicologia e no corpo que se vê recuado frente à exclusão e o rancor do outro.

Na infância, o corpo ainda não completamente enrijecido está embrenhado dos objetos do mundo no tempo e no espaço e a recepção da exclusão o atinge sem tempo para defesas. Diante da agressão recebida no momento do comportamento excludente e preconceituoso, a abertura para a ternura ${ }^{4}$, que a amizade promete, é atacada de forma que o corpo aprende a encolher-se com ressentimento ou a reproduzir a violência. Em ambos os casos, o amor - o cuidado de si e do outro - é subtraído pelo seu oposto, o ódio. Contra tal processo de impedimento da identificação entre os humanos, há de se buscar certa recuperação da sensibilidade para enfrentar o enrijecimento racional, evitando, assim, a identificação com a crueldade e a barbárie (SILVA, 2001).

\footnotetext{
${ }^{4}$ A ternura, segundo a psicanálise freudiana, pode ser compreendida como a sexualidade desviada de sua finalidade e que, nisso, preserva o objeto de amor. Segundo Adorno e Horkheimer (1947/1985), a ternura também é expressão da relação entre natureza e cultura manifesta na experiência social como amor não limitado ao sexo, mas que não deixa de ser sexualidade metamorfoseada em amizade.
} 


\section{OQUE INDICAM AS PESQUISAS?}

O percurso teórico-metodológico da pesquisa contou com as análises qualitativas dos artigos publicados acerca das investigações empíricas realizadas pelos grupos de pesquisa de referência nacional: o LaEP/USP, o ONESSP/UFSCAR e o LEPED/UNICAMP.

Para a escolha e análise dos artigos, utilizou-se os procedimentos de seleção e sistematização da pesquisa documental, mais especificamente, a pesquisa bibliográfica das fontes teóricas e temáticas mencionadas. O caminho metodológico da análise documental prevê um trabalho de "garimpagem", tratamento e interpretação das informações que contribuem na confirmação ou refutação do problema pesquisado. Desse modo, não só a organização, mas o conteúdo e o contexto histórico e, principalmente, político das produções e das fontes em análise são mobilizados, contando, para isso, com a orientação do marco teórico e temático que orienta a pesquisa (PIMENTEL, 2001; ZARDO, 2007).

O método qualitativo de análise dos artigos publicados nos sítios eletrônicos dos laboratórios selecionados teve inspiração no roteiro sistematizado por Lima e Mioto (2007). Para essas autoras, os parâmetros de pesquisa são estabelecidos de forma flexível ao movimento do objeto, ou seja, as análises referem-se às relações entre os dados coletados e a realidade histórica. Desse modo, a leitura da bibliografia selecionada ampara as análises de acordo com etapas investigativas intercruzadas e não lineares que se norteiam pelos seguintes momentos: leitura de reconhecimento do material bibliográfico, leitura exploratória, leitura seletiva, leitura reflexiva ou crítica e leitura interpretativa. Vale citar as considerações de Lima e Mioto (2007) acerca deste último momento:

[...] é o momento mais complexo e tem por objetivo relacionar as ideias expressas na obra com o problema para o qual se busca resposta. Implica na interpretação das ideias do autor, acompanhada de uma interrelação destas com o propósito do pesquisador. Requer um exercício de associações de ideias, transferência de situações, comparação de propósitos, liberdade de pensar e capacidade de criar. O critério norteador nesse momento é o propósito do pesquisador. (LIMA; MIOTO, 2007, p. 41).

Nesse sentido, após leitura prévia dos resumos dos artigos, foram selecionados dezesseis que relatam pesquisas empíricas acerca dos processos de aprendizagem/ interação social de crianças (alunos da educação infantil, Fundamental I e II) consideradas em condições de educação especial inclusiva. Admitiram-se as pesquisas realizadas tanto com os próprios alunos, com ou sem deficiências, como também com os outros agentes envolvidos nos processos educacionais (professores, diretores, coordenadores pedagógicos e pais), além dos artigos que tratam do preconceito no contexto investigado.

No total foram analisados oito artigos do LaEP, sete artigos do ONEESP e um artigo do LEPED. Destaca-se que os dezesseis artigos, publicados em revistas científicas entre os anos de 2009 e 2018, correspondem aos seguintes critérios: conterem relatos de pesquisas empíricas e estarem publicados na plataforma lattes dos currículos dos coordenadores dos laboratórios e/ou nos respectivos sítios eletrônicos, conforme a indicação recebida por e-mail dos próprios coordenadores 5 .

A análise dos artigos selecionados indica que a hipótese inicial que orientou esta investigação, a saber, a de que seria possível identificar aspectos concernentes às faculdades da mimese, da imaginação e da memória, presentes em atividades e práticas pedagógicas do contexto da Educação Especial e Inclusiva, em parte não pode ser respondida. Isso porque nas pesquisas relatadas não há uma explicitação das práticas pedagógicas e/ou das intervenções sociais realizadas com os alunos considerados com necessidades educativas especiais. Desse modo, a ausência de uma descrição metodológica dos procedimentos para a experimentação das atividades desenvolvidas nas salas regulares e nas salas de recursos multifuncionais (SRM) deixa lacunas que precisam ser refletidas para que contribuam com uma formação de professores

\footnotetext{
${ }^{5}$ Embora as publicações do LEPED sejam de grande relevância para o campo dos estudos sobre a diferença no contexto educacional, pela atuação da professora Maria Teresa Montoan na defesa e no estabelecimento de políticas para a Educação especial na perspectiva da inclusão no Brasil, ressalta-se que, até o momento das análises da pesquisa, só foi encontrado um único artigo do laboratório com relato de pesquisa empírica. Ainda assim, tal pesquisa foi realizada com um significativo número e variações de sujeitos de pesquisa: diretores das escolas, coordenadores pedagógicos, professores de AEE, professores do ensino Fundamental I e II, pais de alunos com e sem deficiência de escolas públicas urbanas e rurais das cinco regiões do Brasil, totalizando 3.750 sujeitos de pesquisa.
} 
capazes de pensar sobre as práticas e posturas inclusivas. Certamente, os processos educacionais dos alunos com e sem necessidades especiais de inclusão não podem ser orientados por receitas ou manuais de práticas pedagógicas instrumentalizadas. Aliás, do ponto de vista da atuação dos professores, a necessidade cotidiana de criar variadas formas de ensinar e lidar com seus alunos parece ser a maior vantagem para uma reformulação de práticas escolares menos homogeneizadoras, mas não se pode esquecer a precariedade das condições do trabalho docente para tal. Entretanto, exatamente porque a obstrução da diferença necessita ser enfrentada desde o âmago da constituição social, representando um enorme esforço de resistência e autorreflexão acerca dos próprios preconceitos, não é possível minimizar o silêncio sobre quais caminhos metodológicos foram adotados nas intervenções no contexto da educação especial inclusiva que indicam erros e acertos que colaboram ou dificultam a inclusão.

Apesar da falta de descrição das atividades e práticas pedagógicas derivadas das pesquisas relatadas, que poderiam indicar os aspectos mobilizadores do aprendizado e interação social dos alunos, as análises dos artigos selecionados indicam duas categorias indissociáveis e imprescindíveis para o estabelecimento de uma educação voltada para a valorização da diferença: a primeira diz respeito ao preconceito que atravessa as relações tanto entre os alunos quando entre os professores e os alunos; a segunda refere-se à sensação de insegurança e despreparo dos professores para formularem atividades especiais e promoverem a inclusão dos alunos com necessidades especiais.

\section{DOS ESTUDOS SOBRE O PRECONCEITO DO LAEP/USP}

O Laboratório de Estudos sobre o Preconceito (LaEP) foi concebido pelos professores Lígia Assumpção do Amaral e José Leon Crochík, no Instituto de Psicologia da Universidade de São Paulo, e atua desde 1997 na produção de pesquisas e produções científicas sobre o preconceito ${ }^{6}$. Os estudos do LaEP se fundamentam na Teoria Crítica da Sociedade, em especial nas obras de Theodor W. Adorno, e representam importante contribuição acerca das manifestações do preconceito que permeiam as relações entre os atores que compõem o contexto escolar, sem perder de vista que os limites e avanços de propostas de uma educação inclusiva são inseparáveis das contradições sociais das quais derivam o medo e a autorreflexão que, por sua vez, impulsionam a aliança entre educação e autoritarismo.

O autoritarismo ao persistir na organização social, fixando-se na personalidade, condiciona uma formação voltada para o pensamento endurecido, com indivíduos narcisistas incapazes de reconhecer as possibilidades para a experiência, para a abertura ao novo que só pode advir do contato com a diferença. Nesse sentido, o esforço das políticas para a implementação da perspectiva da educação especial e inclusiva é um bom exemplo para as tentativas de se encontrar brechas para a crítica ao preconceito e à frieza do autoritarismo no campo da Educação. Isso acontece na medida em que essa visão reivindica a convivência entre $o$ estranho e $o$ familiar, possibilitando o reconhecimento da fragilidade que a natureza impõe, e cuja identificação é negada no processo de sua dominação (CROCHÍK; DIAS; RAZERA, 2015).

Em Crochík et al (2013), lê-se que o caráter de padronização da educação é o que permite a adaptação à realidade existente e isso não pode ser tomado como inteiramente inviável, visto que é necessário adaptar-se para reconhecer o que está em volta e sobreviver às demandas externas. Contudo, submeter a experiência com a diferença ao padrão social aceito impede que as crianças possam se identificar umas com as outras e, assim, promoverem relações inclusivas entre todas. Ao contrário, as crianças e adolescentes em meio ao contínuo cerceamento da afetividade e abrigo para a diferença, principalmente na escola, têm encontrado os meios para a manifestação da violência cotidiana. Tal violência se manifesta, em especial, por meio do bullyng, que habita as lembranças escolares de todos os tempos, mas que nas últimas duas décadas tem mobilizado emocionalmente as vítimas a ponto de estar entre as causas do crescente número de suicídios entre as crianças e adolescentes (SOUZA et al, 2017).

No texto Atitudes de professoras do ensino fundamental (CROCHÍK et al, 2009), é possível encontrar como resultado a insegurança das professoras em lidar pedagogicamente com os alunos com

\footnotetext{
${ }^{6}$ Informações extraídas da página eletrônica do LaEP. Disponível em: http://www.ip.usp.br/portal/index.php?option=com_con tent\&view=article\&id=2262\%3Alaep-informes\&catid=358\&Itemid=211\&lang=pt. Acesso em 11/11/2019.
} 
deficiências e necessidades especiais. Apesar da maioria das professoras investigadas manifestar o apoio à lei da inclusão, elas declaram ter dificuldades de trabalhar com alunos com deficiências intelectuais severas. As docentes relatam ainda que não sabem como realizar um planejamento eficiente para o melhor aprendizado dos alunos com necessidades especiais e que se sentem impotentes ao terem que assumir a responsabilidade de implementarem a inserção desses alunos ao mercado de trabalho, sob as metas de uma educação para o desempenho tal como o exigido (CROCHÍK et al, 2009). Esses comportamentos não podem ser tomados somente como decorrentes de preconceitos implícitos e explícitos em relação às exigências de inclusão dos alunos com deficiências, mas antes revelam o despreparo para lidar com aqueles que não respondem aos padrões medianos estabelecidos socialmente. Não se sentir preparado para lidar com a diferença, especialmente aquelas que a natureza biológica impõe, não pode ser considerado, primeiramente, no âmbito das dificuldades pessoais. Pelo contrário, esse despreparo remete às condições enrijecidas de vida que forjam subjetividades com tendências a comportamentos padronizados, irrefletidos e fixados diante de situações em constantes transformações. Ao mesmo tempo, é no campo da educação que residem possibilidades para a resistência individual ao medo de entrar em contato com a diferença e, nisso, à reprodução da lógica da exclusão que permeia as relações na escola (CROCHÍK et al, 2009).

Em Crochík et al (2011), os pesquisadores lembram que, na perspectiva da educação inclusiva, o foco das dificuldades de aprendizagem impulsiona à mudança de ênfase do aluno para a escola. A fim de atender à perspectiva da inclusão não só dos alunos com deficiências, mas também daqueles que no cotidiano escolar são excluídos por apresentarem problemas de relacionamento e disciplinares, toda comunidade escolar deve atuar em conjunto para criar estratégias pedagógicas que não corroborem a exclusão nas próprias salas de aula, criando, nas palavras dos pesquisadores, uma "sala especial dentro da sala regular” (CROCHÍK et al, 2011, p. 569).

Trata-se da escola enfrentar a realidade de que sua orientação para uma formação que prioriza o desempenho e a adaptação ao mundo do trabalho não corresponde mais às necessidades de produções materiais há muito atendidas pelo desenvolvimento tecnológico das máquinas contemporâneas. Desse modo, a escola atual tem a oportunidade e a necessidade de se reinventar, voltando-se para uma formação da convivência democrática, algo que exige não apenas uma consciência sobre a importância do respeito humano para a realização da diferenciação dos indivíduos, mas um intenso investimento na crítica às impossibilidades sociais para tal consciência dentro e fora da escola. Somente uma educação crítica é capaz de reconhecer os obstáculos à inclusão e não abrir mão de uma formação política que reivindique mudanças na realidade social e crie práticas com força o suficiente para se opor à competição, à violência contra a própria diferenciação e a do outro (CROCHÍK et al, 2011).

Na pesquisa que investigou as atitudes de doze professoras da rede municipal de Campo Grande (MS), Crochík et al (2011) afirmam que não só a exclusão reforça o preconceito contra a diferença, mas também as atitudes de superproteção. Ambos os comportamentos atribuem à diferença um caráter de inferioridade decorrente do preconceito. Segundo os pesquisadores, embora, de modo geral, as professoras afirmem a pertinência da educação inclusiva para a melhor formação e convivência dos alunos, também atestam ser imprescindível para a inclusão a presença de professores especializados que atendam às necessidades especiais, suprindo uma formação que elas consideram insuficiente para práticas pedagógicas inclusivas (CROCHÍK et al, 2011).

Neste ponto, vale lembrar que é imputado às professoras especialistas certo conhecimento médico das necessidades especiais, o que remete ao falso conforto que os diagnósticos e laudos clínicos dos alunos com dificuldades de aprendizagem oferecem à escola. Esse conforto se relaciona com a conformação da diferença aos fatores biológicos, que supostamente podem ser ajustados e manipulados com medicamentos psicofármacos, no lugar do interesse na contextualização dos limites e potencialidades destes alunos e das condições objetivas para o seu melhor desenvolvimento educacional. Em tempos em que o campo escolar encontra apoio de forma irrefletida nos discursos que restringem as experiências dos indivíduos ao seu funcionamento biológico, como se as possibilidades de aprendizado da vida dependessem unicamente da intervenção adequada em algum ponto cerebral, é fundamental a crítica da supremacia da medicalização da infância no contexto escolar, que atende muito bem à adaptação aos padrões de eficiência e desempenho exigidos no mundo do trabalho e mantém a gestão da vida sob o controle dos interesses econômicos (SILVA; VAZ, 2016). 


\section{CONTRIBUIÇÕES DO ONEESP/UFSCAR}

O ONEESP ${ }^{7}$ é coordenado pela professora Dra. Enicéia G. Mendes e conta com vinte e cinco pesquisadores provenientes de dezoito programas de pós-graduação de universidades brasileiras. Segundo resumo do projeto, o termo Observatório tem sido usado para denominar uma rede formada por parceiros colaborativos que se unem com a perspectiva de produzir evidências científicas. Essas evidências servem para embasar a definição de prioridades e estratégias de pesquisa e formação, bem como permitir o acompanhamento de progressos, identificar as barreiras e promover os avanços, além de serem potencialmente um veículo poderoso de intercâmbio e formação para todos os envolvidos. As pesquisas realizadas pelo ONEESP analisadas neste trabalho, de modo geral, têm como foco principal avaliações das estruturas e funcionamentos das SRM, em que as atividades, o espaço e os materiais são destinados ao atendimento especializado, de forma complementar aos alunos considerados com necessidades especiais de aprendizado.

Nesse escopo investigativo, esperava-se encontrar resultados de pesquisas que contemplassem os processos educacionais estabelecidos nas SRM. Além disso, eram esperadas análises sobre a formação dos professores especializados em educação especial que contribuíssem para a reflexão sobre de que modo o preconceito, a afetividade, a interação entre professores-alunos e alunos-alunos ocupam lugar nos projetos da educação especial investigados - como está, de certo modo, anunciado na descrição do ONEESP e nos resumos dos artigos selecionados. No entanto, embora os estudos apresentem análises e um importante levantamento quanto à organização, estrutura física, formação dos professores e público atendido, o foco se mantém na implementação das exigências físicas e organizacionais da lei de educação especial inclusiva (ANJOS; CAMPELO, 2013, MATURANA; MENDES, 2017; MENDES et al, 2015). Desse modo, os estudos não contemplam análises sobre os comportamentos ou atividades pedagógicas propostas aos alunos usuários das SRM ou dos processos de ensino-aprendizagem desenvolvidos nas escolas.

Pode-se dizer que as publicações analisadas do ONEESP confirmam uma lacuna nas pesquisas sobre a educação especial que explicam, em parte, a insegurança quanto à própria formação e aos métodos didáticos que podem auxiliar neste contexto. Por se tratar de importante fonte de pesquisas que investigam as estratégias e práticas colaborativas para a efetivação da educação especial inclusiva, os artigos não apresentam em seus resultados certa explicitação das atividades realizadas. Então, como identificar as barreiras e difundir exemplos eficazes de tais práticas?

Ressalta-se que as limitações metodológicas na vasta produção sobre a educação especial e inclusiva também foram apontadas em estudo acerca da inclusão escolar de crianças com Transtorno do Espectro Autista. As autoras do trabalho destacam que, diante das lacunas nas pesquisas, é urgente a necessidade de investigações que contemplem as potencialidades de interação entre as crianças, o que poderia facilitar os aprendizados e inclusão das mesmas (CAMARGO; BOSA, 2009).

De todo modo, em Vilaronga e Mendes (2014) encontram-se indicações que interessam às práticas pedagógicas. Segundo elas, o ensino colaborativo parece ser indispensável na reestruturação das escolas a fim de atender às políticas de Educação Especial na perspectiva da Inclusão. Para tal empreitada, é necessário o aumento de investimentos educacionais que viabilizem a colaboração entre professores da rede das salas regulares e dos especialistas em educação especial, disponibilizando tempo para o planejamento das atividades, materiais pedagógicos e estratégias para as adaptações curriculares adequadas à inclusão dos alunos que não conseguem acompanhar os conteúdos trabalhados (VILARONGA; MENDES, 2014).

Na pesquisa-ação desenvolvida pelas autoras mencionadas, a colaboração entre os professores se mostrou uma estratégia eficaz do ponto de vista dos aprendizados dos alunos, mas também do fortalecimento da relação entre o aluno com necessidades especiais e os professores, a partir do momento que os alunos perceberam a disponibilidades dos professores em acompanhá-los em seus processos cotidianos (VILARONGA; MENDES, 2014).

Já acerca da deficiência intelectual (DI) e escolarização, as análises da ONEESP indicam que a escola e, em especial, os professores, se encontram num campo de inseguranças quanto às formas de lidar

\footnotetext{
${ }^{7}$ Informações extraídas da página eletrônica da ONEESP. Disponível em: http://www.oneesp.ufscar.br/projeto-oneesp. Acesso em 11/11/2019.
} 
com a inclusão de tais alunos (BARBOSA; DUARTE, 2016). O artigo analisado destaca que a escola quando recebe estudantes com DI necessita enfrentar o desafio de adequar seus currículos, métodos e ambientes de modo a auxiliar o processo de socialização e aprendizado dos alunos, considerando suas necessidades especiais. Para além disso, deve contribuir para que as dificuldades intelectuais não sejam tomadas como a identidade destes alunos e, sim, como particularidade que reordena as atitudes e altera a compreensão sobre aprendizagem de todo corpo escolar. A fixação na identidade deficiente constitui o equívoco de que crianças com necessidades especiais aprendem apenas a se socializarem, enquanto as crianças com desenvolvimento típico aprendem também os conteúdos disciplinares. É preciso não esquecer que os avanços com o desenvolvimento cognitivo das crianças com DI dependem da qualidade da intervenção, das ofertas no cotidiano escolar e, principalmente, da superação dos preconceitos das escolas quanto às capacidades de aprendizado e inclusão destes alunos. De modo geral, as análises deste estudo indicam que os avanços do aprendizado de alunos com DI ocorrem quando as práticas docentes não se restringem ao conhecimento abstrato e diversificam os métodos pedagógicos, utilizando recursos materiais apoiados em situações visuais (BARBOSA; DUARTE, 2016).

Pode-se dizer que um dado recorrente em vários estudos (ANJOS; CAMPELO, 2013; BARBOSA; DUARTE, 2016; MATURANA; MENDES, 2017) diz respeito ao fato de que os professores, embora tenham consciência da importância da utilização de diferentes processos de ensino-aprendizagem, sentem muita dificuldade em operacionalizar tais mudanças nas práticas docentes. Isso reforça a sensação de insegurança sobre a própria formação e da falta de interação entre os agentes do corpo escolar para o estabelecimento de práticas colaborativas.

O caráter de exclusão e do bullyng com as crianças com DI também pôde ser percebido em Maturana e Mendes (2017). A pesquisa investiga a transferência dos alunos de escolas especiais para escolas regulares e vice-versa, sob a ótica dos próprios alunos com DI. Nos relatos dos estudantes, identificou-se situações de isolamento em sala de aula, ridicularização e zombarias quanto às dificuldades de aprendizagem, falta de atenção quanto às necessidades dos alunos, a ponto dos entrevistados se sentirem mais acolhidos nas escolas especiais, formando vínculos afetivos com outras crianças, professores e funcionários e atribuindo à escola regular apenas a expectativa de aprender a ler e escrever (MATURANA; MENDES, 2017).

\section{OLEPED/UNICAMP}

No sítio eletrônico do Laboratório de Estudos e Pesquisas da Diferença (LEPED) ${ }^{8}$ encontra-se que a motivação para seu surgimento reside na necessidade de se congregarem esforços e competências de pessoas de diferentes áreas do conhecimento para planejar e executar projetos que visem a transformação das escolas, de modo a tornarem-se ambientes educacionais inclusivos. Coordenado pela Profa. Dra. Maria Teresa Eglér Montoan, o LEPED pertence ao Departamento de Ensino e Práticas Culturais da Universidade de Campinas (UNICAMP) e realiza atividades ligadas à pesquisa, à extensão e ao ensino, com foco na formação de professores para uma educação inclusiva. Destaca-se, ainda, que as publicações do LEPED, em especial, de autoria e ou organização de Montoan (1999, 2013, 2015), são referências para a formulação das políticas para a educação especial na perspectiva da inclusão, constituindo parte do acervo disponibilizado pelo Ministério da Educação (MEC) e embasando a discussão em diversos meios de veiculação da educação inclusiva.

O artigo do LEPED que foi analisado apresenta os resultados de pesquisa empírica realizada com dirigentes, coordenadores pedagógicos, professores de atendimento especial especializado (AEE) e de ensino Fundamental I e II e pais de alunos com e sem deficiências, das cinco regiões brasileiras. Montoan (2015) sistematizou os resultados em três categorias de análises: percepções e posições dos sujeitos sobre inclusão escolar; mudanças na escola comum decorrentes da implantação da Educação Especial, na perspectiva da inclusão; fatores impulsores e restritivos intervenientes da implantação da Educação Especial, na perspectiva da inclusão.

\footnotetext{
${ }^{8}$ Informações extraídas da página eletrônica do LEPED. Disponível em: https://www.leped.fe.unicamp.br/apresentacao. Acesso em $11 / 11 / 2019$.
} 
A partir do número de matrículas de alunos com deficiências em escolas regulares, a pesquisa revelou altos índices de opiniões favoráveis nas cinco regiões do país. No que se refere às mudanças na escola e aos fatores propulsores da implantação da Educação Especial Inclusiva, os atores envolvidos no contexto educacional só apresentaram benefícios na convivência com alunos com deficiências (MONTOAN, 2015). Assim, a pesquisa apresenta certa contradição com as outros estudos do LaEP e ONEESP, realizados com professores e diretores, uma vez que essa não explicita nenhuma dificuldade objetiva de se operacionalizar as práticas pedagógicas, tampouco relata qualquer manifestação de preconceito dos atores que compõem os contextos da educação inclusiva. Apesar disso, a pesquisa é importante por revelar uma consciência de que a convivência com a diferença deve ser enfrentada em favor do direito de todos à educação, da busca contínua da formação de professores e do melhor desenvolvimento de alunos com e sem deficiência. Ainda que não tenham especificado momentos ou aspectos de manifestações do preconceito, os professores, ao se referirem ao trabalho em parceria com o AEE, afirmaram que residia ali a possibilidade de superar os preconceitos e viabilizar práticas, métodos e planejamentos na sala regular capazes de gerar melhorias na educação (MONTOAN, 2015).

Montoan (2013) afirma que entre as dificuldades em transformar as escolas em espaços para a valorização da diferença, se opondo às normativas que operam dentro e fora da escola, estão os obstáculos de caráter subjetivo, que por estarem arraigados na socialização dos sujeitos e, nisso, naturalizados em preconceitos, se tornam os mais difíceis de superar. Sem a disposição dos sujeitos para enfrentarem sua própria rigidez e os elementos inconscientes que alimentam os preconceitos, a caminhada para o estabelecimento de uma escola inclusiva se tornará mais lenta e custosa.

\section{NOTAS FINAIS}

Desse modo, a partir das importantes contribuições dos laboratórios estudados, conclui-se que o fato dos professores, recém-saídos da graduação e, muitas vezes, dos cursos de formação continuada, afirmarem que não foram preparados para lidar com alunos considerados da Educação Especial Inclusiva, parece indicar que tanto os estudos teóricos que propõem a reflexão acerca da formação dos preconceitos de ordem sociais, quanto aqueles que investigam empiricamente os processos de aprendizagem considerando as necessidades especiais dos alunos encontram barreiras na formação dos professores. Por conseguinte, enfrentar essas barreiras poderia contribuir para a superação da insegurança que todos aprendemos a sentir frente às diferenças. Insegurança constituída indubitavelmente pelas determinações sociais para a indiferenciação dos indivíduos.

De certo que não é possível cobrar uma formação de professores capaz de conhecer e saber intervir em todas as especificidades dos alunos. Contudo, é urgente um processo formativo que reconheça as formas implícitas e explícitas dos preconceitos naturalizados nas relações sociais. Ademais, é essencial que essa formação seja consciente de que o incentivo ao fortalecimento de vínculos afetivos entre os alunos, mas também entre toda comunidade escolar (família, professores, gestores, funcionários) é o que tem sido revelado nas pesquisas sobre o preconceito e a educação especial inclusiva, com destaque para os estudos do LaEP/USP, como o fator capaz de contribuir para relações inclusivas e, nisso, para o melhor desenvolvimento intelectual e social de todos os envolvidos (CROCHÍK, 2009; 2014; CROCHÍK et al, 2011; 2013).

Ainda que os programas educacionais tenham causado paulatinamente a inclusão de alunos marginalizados pelas condições de desigualdades sociais ${ }^{9}$, ainda é preciso converter o caminho da educação que aliena e, nisso, contribui para a violência e o preconceito, para outro, que resista à própria frieza aprendida. A meta educacional a ser seguida por toda a sociedade, portanto, deve ser a da educação em prol do cuidado colaborativo com as fragilidades humanas e culturais. Com isso, não se pode diminuir

\footnotetext{
${ }^{9}$ Crochík (2012) assinala que, "no Brasil, em 2003, o número de matrículas de alunos com necessidades educacionais especiais no ensino regular era de $29 \%$ e, em 2009, passou para 61\%.” (p. 215). Tais dados, retirados do INEP/MEC, revelam que a escola no Brasil tem percebido e se empenhado para incluir cada vez mais os grupos que se afastaram da escolarização se contrapondo à exclusão. Contudo, cabe lembrar que atualmente este movimento progressivo tem sofrido ameaças políticas, na medida em que as verbas destinadas à educação diminuem substancialmente e que a autonomia do professor tem sido cerceada.
} 
a responsabilidade política e institucional no que se refere aos investimentos na formação contínua dos professores, na gestão compartilhada em busca de práticas que adaptem o currículo e os ambientes sem perdas qualitativas e, em especial, na compreensão de que os aclamados diagnósticos sobre as deficiências não devem servir de justificativa para a inabilidade de todos em encontrarem os meios para superarem os obstáculos frente ao diferenciado.

\section{REFERÊNCIAS}

ADORNO, T. W. Educação e emancipação. (W. L. Maar, Trad.). São Paulo: Paz e Terra, 1995. pp.139-154.

ADORNO, T. W.; HORKHEIMER, M. Dialética do esclarecimento: fragmentos filosóficos. (G. A. Almeida, Trad.). Rio de Janeiro: Jorge Zahar, 1985, 223p. (Original publicado em 1947).

AGUIAR, J. S. O jogo no ensino de conceitos a pessoas com problemas de aprendizagem: uma proposta metodológica de ensino. Revista Brasileira Educação Especial, Marília, 2003. v. 9, n.1, Jan.- Jun., pp. 79-108.

AMIRAliAn, M. L. T. M. Desmistificando a inclusão. Psicopedagogia, São Paulo, 2005, v. 22, n. 67, pp. 59-66. Disponível em: http://bdpi.usp.br/single.php?_id=001472287. Acesso em 16 nov. 2017.

ANHÃO, P. P. G.; PFEIFER, L. I.; SANTOS, J. L. Interação social das crianças com síndrome de down na educação infantil. Revista Brasileira Educação Especial, Marília, 2010. v. 16, n. 1, Jan. - Abr., pp. 31-46. Disponível em: http://www.scielo.br/scielo.php?script=sci_arttext\&pid =S1413-5382010000100004. Acesso em 30 out. 2016.

ANJOS, H. P. dos; CAMPELO, C. da S. Perfil das salas de recursos: construindo uma leitura acerca das políticas recentes para a inclusão escolar. Poiésis: Unisul, Tubarão - SC, v. 7, n. 11, 2013, pp. 8395. Disponível em: http://www.oneesp.ufscar.br/perfil-das-salas-de-recursos-construindo-uma-leituraacerca-das-politicas-recentes-para-a-inclusao-escolar. Acesso em 14 abr. 2018.

BARBOSA, M. O.; DUARTE, L. N. Deficiência intelectual e escolarização: uma análise das produções científicas. Comunicações. Piracicaba, v. 23, n. 3, 2016, p. 351-368. Disponível em: https:// www.metodista.br/revistas/revistas-unimep/index.php/comunicacoes/article/view/2925. Acesso em 20 nov. 2017.

BRASIL. Ministério da Educação. Plano de Desenvolvimento da Educação: razões, princípios e programas. Brasília: MEC, 2007. Disponível em: http://portal.mec.gov.br/secretaria-de-educacaoespecial-sp-598129159/legislacao. Acesso em 02 jan. 2017.

BRASIL, Ministério da Educação. Secretaria de Educação Especial. Política Nacional de Educação Especial na Perspectiva da Educação Inclusiva. Brasília: MEC, SEESP, jan. 2008. Disponível em: http://portal.mec.gov.br/secretaria-de-educacao-especial-sp-598129159/legislacao. Acesso em 02 jan. 2017.

CAMARGO, S., P. H.; BOSA, C. A. Competência social, inclusão escolar e autismo: revisão crítica da literatura. Psicologia \& Sociedade, vol. 21, 2009, pp. 65-74. Disponível em: http://www.scielo.br/ scielo.php?script=sci_arttext\&pid=S0102-71822009000100008. Acesso em 21 mar. 2018.

COMFOR. Aperfeiçoamento: “A gestão do desenvolvimento inclusivo na escola” Módulo 3 Princípios do planejamento inclusivo na escola. São Paulo: UNIFESP, 2015. Disponível em: http:// comfor.unifesp.br/?page_id=774. Acesso em 10 jan. 2017.

CROCHÍK, J. L. Fatores psicológicos e sociais associados ao bullyng. Psicologia política, vol. 12, n. 24, mai-ago, 2012, pp. 211-229. Disponível em: http://pepsic.bvsalud.org/scielo.php?script=sci_ arttext\&pid=S1519-549X2012000200003. Acesso em 05 dez. 2017. 
CROCHÍK, J. L. Atitudes de professores em relação à educação inclusiva. Psicologia: ciência e profissão, Brasília, v. 29, n. 1, 2009, pp. 40-59.

CROCHÍK, J. L. A corporalidade e a formação humana: uma análise a partir da teoria crítica. Discorpo, São Paulo, PUC/SP, 1999. n. 9, pp. 11-21.

CROCHÍK, J. L. Preconceito, indivíduo e sociedade. Temas em psicologia. Ribeirão Preto, vol. 4, n. 3, 1996. pp. 47-70. Disponível em: http://pepsic.bvsalud.org/pdf/tp/v4n3/v4n3a04.pdf. Acesso em: 05 mai. 2020.

CROCHÍK, J. L., et al. Análises de concepções e propostas de gestores escolares sobre o bullyng. Acta Scientiarum Educação. Maringá, vol. 36, n. 1, jan-jun, 2014, pp. 115-127. Disponível em: http://periodicos.uem.br/ojs/index.php/ActaSciEduc/article/view/21940. Acesso em 10 fev. 2018.

CROCHÍK, J. L., et al. Educação inclusiva: escolha e rejeição entre alunos. Psicologia \& Sociedade. 2013, pp. 174-184. Disponível em: http://www.scielo.br/scielo.php?script=sci_arttext\&pid =S0102-71822013000100019. Acesso em jun. 2018.

CROCHÍK, J. L., et al. Análise de atitudes de professoras do ensino fundamental no que se refere à educação inclusiva. Educação e pesquisa. São Paulo, v. 37, n. 3, set-dez, 2011, pp. 565-582. Disponível em: http://www.scielo.br/scielo.php?pid=S151797022011000300008\&script=sci_ abstract\&tlng=pt. Acesso em 17 jan. 2018.

CROCHÍK, J. L.; DIAS, M. A. de L e; RAZERA, K. D. M. F. Teoria Crítica da sociedade, investigação social empírica e educação inclusiva. Imagens da Educação, 2015. v. 5, n. 2, pp. 01-09. Disponível em: http://periodicos.uem.br/ojs/index.php/ImagensEduc/article/view/26762. Acesso em 06 nov. 2016.

LIMA, T. C. S. de; MIOTO, R. C. T. Procedimentos metodológicos na construção do conhecimento científico: a pesquisa bibliográfica. Revista Katálysis. Florianópolis, UFSC/SC, 2007. vol. 10, n. especial, pp. 37-45.

MATURANA, A. P. P. M.; MENDES, E. G. Inclusão e deficiência intelectual: escola especial e comum sob a ótica dos próprios alunos. Educ. ver [on line]. N. 66, 2017, pp. 209-226. Disponível em: http://www.scielo.br/scielo.php?pid=S0104-40602017000400209\&script=sci_abstract\&tlng=pt. Acesso em 02 de abr. 2018.

MENDES, E. G. et al. A formação dos professores especializados segundo os pesquisadores do Observatório Nacional de Educação Especial. Educação e Fronteiras, v.5, n. 14, 2015, pp. 84-95. Disponível em: http://ojs.ufgd.edu.br/index.php/educacao/article/view/3775. Acesso em 01 jul. 2018..

MONTOAN, M. T. E. Por uma escola para todos, 1999. (Texto mimeografado)

MONTOAN, M. T. E. Para Uma escola do século XXI. [Recurso Eletrônico]. Organizado por Maria Tereza Egler Montoan; Ilustrador: Gustavo Machado Tomazi. Campinas, SP: UNICAMP/BCCL, 2013. 122p. Disponível em: http://www.bibliotecadigital.unicamp.br/document/?code=000922545\&opt=1. Acesso em 02 nov. 2016.

MONTOAN, M. T. E . Educação especial na perspectiva inclusiva: o que dizem os professores, dirigentes e pais. Diálogos e pesquisa em Educação Especial, 2015, v. 2, n. 1, pp. 23-41.

PIMENTEL, A. O método da análise documental: seu uso numa pesquisa historiográfica. Cadernos de Pesquisa, 2001, n. 114, pp. 179-195. Disponível em: http://www.scielo.br/scielo.php?pid=S010015 742001000300008\&script=sci_abstract\&tlng=pt. Acesso em 01 mai. 2017. 
QUEIROZ, O. A de; ENUMO, S. R. F; PRIMI, R. Desempenho de Crianças Com e Sem Necessidades Especiais em Provas Assistidas e Psicométricas. Revista Brasileira Educação Especial, Marília, 2013. v. 19, n. 3, Jul. - Set. p. 425-446. Disponível em: http://www.scielo.br/pdf/rbee/v19n3/09.pdf. Acesso em 11 nov. 2016.

SALGADO, Mara. Entrelaçamento do amor e do pensamento na infância em Theodor W. Adorno: um estudo sobre mimese, imaginação e memória. 2017. Tese de doutorado - Curso de Pós-Graduação em Educação, Departamento de CCE, Universidade Federal de Santa Catarina, Florianópolis, 2017, $152 f$.

SILVA, D. J. A Educação para a amplitude de experiência. Perspectiva, Florianópolis, 2001, v. 19, n.2, jul./dez., pp. 331-349. Disponível em: https://periodicos.ufsc.br/index.php/perspectiva/article/ view/10232. Acesso em 20 jul. 2017.

SILVA, D. J.; VAZ, A. F. A emergência do sujeito cerebral e suas implicações para a educação. Childhood \& Philosophy, v. 12, n. 24, mai-ago, 2016, pp. 211-230. Disponível em: http://www. redalyc.org:9081/articulo.oa?id=512055734002. Acesso em: 02 mar. 2018.

SOUZA, G. S de et al. Revisão de literatura sobre suicídio na infância. Ciência Saúde Coletiva. Rio de Janeiro, v. 22, n. 9, 2017, pp. 3099-3110. Disponível em: http://www.scielo.br/scielo. php?script=sci_arttext\&pid=S1413-81232017002903099. Acesso em 04 mai. 2018.

VILARONGA, C. A. R.; MENDES, E. G. Ensino colaborativo para o apoio à inclusão escolar: práticas colaborativas entre os professores. Revista brasileira de estudos pedagógicos. [on line] v. 95, n. 239, 2014, pp. 139-151.

ZARDO, S. P. Enfoques teórico-metodológicos da pesquisa em Educação Especial: análise epistemológica das produções da ANPED 2007. Disponível: http://www.histedbr.fe.unicamp.br/acer_ histedbr/seminario/seminario8/_files/vPEfcpDo.pdf. Acesso em 01 mai. 2017. 